\title{
Probiotics and the envisaged role in treating human infertility
}

\author{
Nagham Younis ${ }^{*}$ (D) and Adel Mahasneh
}

\begin{abstract}
Background: Considerable attention is being directed nowadays towards using probiotics as an alternative therapy in treating several human diseases including gastrointestinal tract diseases especially colorectal cancers, cardiovascular diseases, hyperlipidemia, and blood pressure cases. However, infertility as affected by the microbiome and the probable role of probiotics in alleviating infertility problems did not receive the deserved attention, especially in IVF patients with male or female factors.

Main body: In this review, we tried to draw the attention of researchers in the medical settings to the importance of the forthcoming role of probiotics use in elucidating the role of the microbiome in infertile patients. The hope is to attain the best performance of both male and female reproductive systems and to shed some light on infertility problems.

Conclusion: More in vivo experiments are still needed to address many aspects of probiotics like proper administration, exact functional strains, required dose, application method, duration of treatment, and combination with antibiotics before considering probiotics as an alternative treatment.
\end{abstract}

Keywords: Probiotics, Infertility, Microbiome, Bacterial vaginosis, Lactobacillus species, Fertility boosting

\section{Background}

The demand for healthy food is a global issue, and a pressing need exists for other natural resources that can be used as alternatives to regular foods and can be introduced in nutraceutical and therapeutic industries. The best candidate in this endeavor is the use of probiotics which received a great interest in the last 15 years [1]. The idea behind probiotics use is to have a healthy lifestyle by improving the internal microbiota [2] and to find out the most suitable microorganism or consortium of microorganisms that improve health or reduce/treat some diseases [3]. This goal can be achieved by having the good bacteria in the right place.

The history of probiotics goes far away back to the Greek and Latin civilizations where the word probiotics came from a combination of "Pro: for, bios: for life" [4]. In the early twentieth century, Elie

\footnotetext{
* Correspondence: naghamyounis@yahoo.com

Department of Biological Sciences, School of Science, The University of Jordan, Amman 11942, Jordan
}

Metchnikoff, a Nobel Prize winner, pointed to the positive effect of fermented milk on the gut microbiota and the body health, in general. His preliminary observations awarded him the privilege of being the "father of probiotics." In 1965, Lilly and Stillwell used this term for the first time to define probiotics as microorganisms and/or substances secreted from living microorganisms to confer a better health directly or indirectly or to enhance the growth of others [5].

Probiotics definition had been modified afterward to include the beneficial bacteria that improve the internal microbiome. The latest description of probiotics was proposed by Food and Agriculture Organization (FAO) in 2002 to be: "Live microorganisms, which, when administered in adequate amounts, confer a health benefit on the host" [6]. In October 2013, the participant scientists of International Scientific Association for Probiotics and Prebiotics (ISAPP) emphasized the previous concept of probiotics proposed by FAO. This highlighted the introduction of the concept of prebiotics and their

\section{Springer Open}

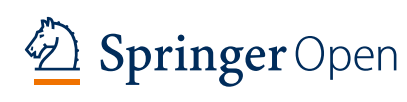

(C) The Author(s). 2020 Open Access This article is licensed under a Creative Commons Attribution 4.0 International License, which permits use, sharing, adaptation, distribution and reproduction in any medium or format, as long as you give appropriate credit to the original author(s) and the source, provide a link to the Creative Commons licence, and indicate if changes were made. The images or other third party material in this article are included in the article's Creative Commons licence, unless indicated otherwise in a credit line to the material. If material is not included in the article's Creative Commons licence and your intended use is not permitted by statutory regulation or exceeds the permitted use, you will need to obtain permission directly from the copyright holder. To view a copy of this licence, visit http://creativecommons.org/licenses/by/4.0/. 
pivotal role in helping probiotics to carry out their expected role.

Prebiotics are non-digestible carbohydrates such as fructo-oligosaccharides (FOS) and inulin among many others that help probiotic microorganism to flourish. They promote the growth of beneficial bacteria over the harmful ones. The combination of both probiotics and prebiotics is known as synbiotics and gives a synergistic impact [7].

It is well known that probiotics act to boost immunity system [8], eliminate hostile bacteria by excluding colonization [9], prevent infection, and improve overall health of the gastrointestinal tract (GIT) [10]. Recently, attention was directed towards the effect of probiotics on other sites of the body like the skin, oronasopharyngeal cavity, and genital tract.

According to the World Health Organization (WHO), infertility is defined as "a disease of the reproductive system defined by the failure to achieve a clinical pregnancy after 12 months or more of regular unprotected sexual intercourse." A global concern is growing as the percentage of both male and female infertility is rising [11]. Epidemiological studies revealed that around 10\% of global population in reproductive age are suffering from infertility problems [12].

Counseling an infertile couple is a challenge to any physician, as infertility is a multifactorial issue, and vaginal microbiome could be the least to think about. But, according to the recommendations issued by "Human Microbiome Project" (HMP) in the USA (2007), the vagina is considered a major site of studying bacterial microbiome in human body [13]. Nowadays, it is well known that the presence of certain strains of beneficial bacteria in the female genital tract is a key for solving many infertility difficulties. Studies have indicated that the vagina is dominated by Lactobacillus species [14].

The positive effect of probiotics on fertility does not show a clear separation line between males and females, as the female infertility induced by imbalance of vaginal microbiome (VMB) may affect the sperm parameters inside the female reproductive tract [15].

The probiotics influence on fertility and their role in promoting fecundity could be discussed from two main angles: firstly, male fertility and the potential anti-oxidant impact of probiotics on sperm parameters, testicular histopathology, and testosterone level; secondly, female fertility and the effect of probiotics on maintaining the bacterial balance in the vagina, treatment of bacterial vaginosis, and subsequent effect on amelioration of inflammation. Effects of probiotics on assisted reproductive technology (ART), pregnancy complications, and menopausal infections should be considered as well.

\section{Main text}

\section{Probiotics mechanisms of action}

Lactobacilli spp., as the best-studied probiotic bacteria, display several mechanisms to protect vaginal environment from pathogens. The most significant ones are as follows: [16] production of lactic acid that provides pathogenic exclusion ability by lowering $\mathrm{pH}$ to $3.5-4.7$ and contribution to indirect pathogenic inhibition by efficient acid cervico-vaginal human mucus ([17, 18] production of bacteriocins which are antimicrobial peptides (AMP) and proteins, produced as a response of imbalance of vaginal microbiome, to protect the host against microbial invasion $([19,20]$ blocking the colonization of vaginal pathogens as a result of displacement and exclusion competition by Lactobacilli bacteria [17]; and [21] promotion of immunomodulation mechanisms by provoking innate immunity system, producing $\mathrm{H}_{2} \mathrm{O}_{2}$, and stimulating anti-inflammatory action [22].

\section{Probiotics and male fertility Obesity and old age induced male infertility}

A significant proportional relationship between obesity and male sub-fertility has been noticed. It was reported that obese men have higher percentage of poor semen quality [23]. Testosterone deficiency is another side effect of obesity in men who were found to have low sperm count and motility [24]. On the other hand, inevitable testosterone reduction is related to old age in men. This testosterone deficiency is accompanied with increased body fat and reduced libido and sexual activity, in addition to lower spermatogenesis [25].

\section{Effects of probiotics on oxidative stress, testosterone level, testicular histopathology, and sperm quality}

Male infertility related to low sperm parameters constitutes around $50 \%$ of the infertility problem [26]. One of the major factors affecting sperm parameters and testicular histology is obesity. High-fat diet has a prominent role in increasing oxidative stress and lowering antioxidant effect [27]. Elevation of reactive oxygen species (ROS) may have a detrimental effect on sperm quality and hence fertilization potential [28]. The previous study was supported by another one in which a combination of three selected strains of probiotics (Lactobacillus brevis, L. salivarius, L. plantarum) was used as vaginal tablets to treat bacterial vaginosis, in order to explore the protective effect of probiotics on sperm quality against damaging ROS. It has been shown that this probiotic combination inhibited sperm lipid peroxidation and maintained human sperm motility and vitality [19].

Several researches studied the deleterious effect of obesity on male fertility of murine model and the positive effect of probiotics in opposing the adverse influence of high-fat diet. Ibrahim et al. [29] used male mice 
model to study the enhancing effect of probiotics on their impaired fertility. Mice fed with high-fat diet only showed significant increase in serum levels of cholesterol, triglycerides, low-density lipoprotein, high-density lipoprotein, and testosterone and decrease of sperm parameters (count, motility, and morphological abnormalities), besides atrophy and degeneration of seminiferous tubules. On the other hand, penis length and relative weight of testes were not affected. The hostile impact of hyperlipidemia was significantly ameliorated by using selenium-enriched probiotics as testicular tissue injury was reduced, while testosterone level and sperm parameters were improved. They concluded that selenium-enriched probiotics improve male fertility in hyperlipidemic status.

Chen et al. [30] studied the anti-oxidative and protective effects of probiotics against sperm damage induced by high-fat diet in rats. They exposed the test group to high-fat diet to measure the oxidative stress, sperm count, motility, viability, and DNA integrity. They noticed a significant elevation of oxidative stress and lipid peroxidation, and a significant drop in sperm count, motility, viability, and DNA stability. All the adverse effects of all tested parameters were reversed in male rats served with high-fat diet supplemented with probiotics. Sperm DNA damage was significantly lower than the test group but still higher than the control group, which indicates that probiotics reduce the damaging effect of high-fat diet on sperm DNA to some level.

A recent study by Dardmeh et al. [12] demonstrated that probiotics could be an alternative solution in eliminating obesity drawbacks on semen quality. The study was done on male mice to investigate the effect of probiotics (Lactobacillus rhamnosus) on sperm kinematic parameters, testicular weight, lipid profiles, and reproductive hormones such as follicle stimulating hormone (FSH), luteinizing hormone (LH), and testosterone. They found that Lactobacillus rhamnosus has a reduction effect on the weight of mice fed with fat diet. In addition, some sperm biomarkers like motility and reproductive hormones were maintained in male mice fed with fat diet supplemented with probiotics. They postulated that probiotics have a positive effect on male fertility by either direct or indirect influence. The direct effect improves spermatogenesis and maturation process whereas the indirect effect works out by eliminating the adverse effects of obesity and elevating the total antioxidant capacity.

Testosterone level is not affected by obesity only; increasing age is another factor that reduces the circulating level of testosterone in the blood. Poutahidis et al. [31] tested the hypothesis that probiotic Lactobacillus reuteri may prevent testicular atrophy due to obesity and age factors in male mice. Histopathological studies of testicular tissue of probiotic-fed aged mice showed healthy seminiferous tubules and Leydig cells, which usually show atrophy in aged mice. A distinguished level of circulating testosterone was reported in aged mice treated with probiotics Lactobacillus reuteri. These novel findings suggest that probiotics could be used as a natural therapy for male hypogonadism associated with old age.

Synbiotic impact of the medicinal plant dandelion (Taraxacum officinale) and probiotics on testicular histopathology and semen quality of male lambs was evaluated by Zeitoun et al. [32]. Dandelion leaves and roots have been used as a traditional medicine long time ago. It is used to treat constipation and liver, gall bladder, kidney, and joint problems. Nevertheless, dandelion plant was found to cause anti-fertility effect in vivo, such as a prominent drop in testosterone level and spermatogenesis apoptosis. These findings were attributed to generalized and localized edema. Histological results showed a substantial improvement in the testicular tissue of lambs treated with probiotics. It has been reported that probiotics have anti-oxidative stress effect that protects sperm from free radicals. Synbiotic mixture of dandelion and probiotics attenuates the anti-fertility action of dandelion on spermatogenesis and testosterone production.

A recent study was carried out by Valcarce et al. [33] to evaluate the effect of two selected anti-oxidant probiotic strains (Lactobacillus rhamnosus CECT8361 and Bifidobacterium longum CECT7347) on sperm criteria of asthenozoospermic (low motility) men. Four parameters were evaluated: sperm motility, cellular viability, DNA fragmentation, and level of ROS. Viability was not affected while the other three tested parameters demonstrated a significant improvement after probiotic treatment. These findings give an evidence of the importance of using probiotics to improve fertility of human males.

The first placebo-controlled study was conducted by Maretti and Cavallini [34] and reported a significant augmentation in testosterone level and sperm quality of infertile men after using a combination of prebiotic/probiotic therapy. Data showed a direct impact of prebiotic/probiotic therapy on the function of pituitary gland in terms of enhancing FSH and $\mathrm{LH}$ serum levels. Tremellen [35] proposed the GELDING theory (Gut Endotoxin Leading Decline in Gonadal function) that finds a strong relationship between gut microbiota and testicular capacity. Tremellen et al. [36] found that impaired gut mucosa with a leakage of endotoxin-containing bacteria to systemic circulation is associated with defected function of Sertoli and Leydig cells. 
Tirandaz et al. [37] have assumed that there is a substantial potential of gut microbiota and treatment of sexual dysfunction. This hypothesis is based on a strong evidence that sexual problems are affected negatively by hormonal disturbances, stress, obesity, hypertension, and diabetes. Since many studies show that prebiotics and probiotics are the key regulators of microbiota improvement, then they may have an influential therapeutic impact on the abovementioned disturbances.

\section{Probiotics and female fertility}

A balanced environment of vaginal microbiota acts as a gatekeeper of female reproductive system and plays a key role in protecting it from infections that may ascend to upper reproductive tract and lead to many gynecological complications. It is estimated that around 7.5 million women in the reproductive age (15-44 years) are suffering from infertility problem, according to recent statistics in 2016 (National Center for Health Statistics) [38]. It is well known that any infection in the female reproductive system could be a serious threat to fertility as well as pregnancy. Therefore, bacterial vaginosis (BV) has an adverse effect on pre-term delivery of low-weight infants, implantation rate in assisted reproductive technology, and post-partum complications.

\section{Normobiosis and dysbiosis of female genital tract}

More than 200 bacterial species are colonizing the vaginal microbiota [39]. The most predominant species are of the genus Lactobacillus and found in $70 \%$ of the women with healthy vaginal microbiome [40]. It was reported that four species of Lactobacillus are the most abundant among other bacterial strains. L. crispatus is the most dominant Lactobacillus species followed by $L$. jensenii, L. iners, and L. gasseri [41]. Less dominant Lactobacillus spp. that have been identified are Lactobacillus rhamnosus, Lactobacillus plantarum, Lactobacillus vaginalis, Lactobacillus salivarius, and Lactobacillus coleohominis [14].

Other non-Lactobacillus dominant strains that are found in about $20-30 \%$ of women with healthy VMB are Gardnerella, Corynebacterium, Atopobium, Anaerococcus, Prevotella, and others [41]. Therefore, the presence of Lactobacillus spp. has been considered a substantial biomarker for assessment of healthy vaginal microbiota. Normobiosis of genital tract is defined as a microbiome with dominance of Lactobacillus spp. and other obligate anaerobic bacteria. On the other hand, dysbiosis is defined as an imbalance of VMB and dominance of pathogenic microorganisms, such as Mycoplasma, Ureaplasma, and Candida. Gynecological pathogenic effects that may accompany dysbiosis include sexually transmitted diseases (STDs), bacterial vaginosis (BV), adhesions, tubal mucosal damage, pelvic pain, ectopic pregnancy, pre-term labor, post-partum complications, cancers of reproductive tract, and infertility [42].

\section{Fluctuation of vaginal microbiota}

Vaginal ecosystem is influenced drastically by many factors during woman's life cycle, such as hormonal changes, menstrual cycle, pregnancy, menopause, age, sexual behavior, antibiotic treatment [43], hygienic habits, and ethnicity [14]. For example, the ratio of $L$. crispatus has been found to be stable during menses, while $L$. iners has increased significantly during the same period and returns to its normal ratio after that [43]. However, another study showed that the level of $L$. crispatus is dropped 100 times during menstrual cycle, while the level of L. iners and many other Lactobacillus strains increased in women with healthy VMB [44].

\section{Bacterial vaginosis}

Microbial vaginal ecosystem is considered pathogenic once the bacterial composition exceeds the "normal" fluctuation range. Bacterial vaginosis (BV) is defined as a vaginal disorder that is characterized by an interruption of commensal bacterial habitat in the vagina and a colonization of pathogenic microorganisms [45]. In BV, a significant decline in Lactobacillus spp. is detected with a higher overgrowth of other pathogenic bacteria like Gardnerella spp., Atopobium spp., Prevotella spp., and Mobiluncus spp. [39]. The imbalanced microbiota in the vagina is associated with a higher $\mathrm{pH}$ and reduction of lactic acid level [18] while the hostile pathogens will induce the production of mucin-degrading enzymes (e.g., sialidases and mucinases) that disrupts the mucus coating vaginal epithelium, therefore interfering with a substantial barrier against infection [46]. In addition, it has been shown by Harwich [47] that those pathogenic strains can form a polymicrobial biofilm that allows adherence of other pathogenic species. This dysbiotic condition is considered as the most common cause of sexually transmitted diseases (STDs) [48], urinary tract infections (UTIs), and infertility. Bacterial vaginosis was estimated to reach approximately around 19\% in women suffering from infertility problems [49].

\section{Uses of probiotics as alternative therapy in fertility preservation, pregnancy, and menopause}

Based on many studies, it was concluded that exogenous administration of Lactobacillus probiotics has the capability of restoration of vaginal microbiome and hence improves fertility, pregnancy outcome, and menopausal infection. Bhandari and colleagues worked extensively to verify the efficacy of Lactobacillus plantarum in competitive exclusion of sperm-agglutinating Escherichia coli (E. coli) bacteria. Their results proved that $L$. plantarum has a significant displacement competence of $E$. coli 
colonization based on the presence and the count of $E$. coli. bacteria. This finding reflects a substantial role of $L$. plantarum in infertility management $[21,50]$. The previous findings were supported by another study of the same group who used the mice model to assess the probiotics effect as a therapeutic alternative to restore fertility. They treated the therapeutic group with $E$. coli for 10 days intravaginally, and then, they administered $L$. plantarum for another 10 consecutive days. The fertility of the therapeutic group was normal compared to the control group, which reinforces the postulation of using Lactobacillus probiotics as a therapeutic agent in restoring infertility induced by sperm-agglutinating $E$. coli. Anti-inflammatory effect of $L$. plantarumi in ameliorating LPS-mediated inflammation-induced infertility was studied also, and the results have affirmed the potential response of probiotics in attenuating LPS-induced inflammation by upregulation of anti-inflammatory cytokines. These findings were verified by histopathological examination of female reproductive organs and mating tests to confirm fertility potential [51].

\section{Restoration of vaginal microbiota}

One of the first reports of probiotics effectiveness by using well-characterized probiotic strains in treating BV was provided by Anukam et al. [16]. They studied the effect of capsules containing Lactobacillus rhamnosus and Lactobacillus reuteri on forty Nigerian women with bacterial vaginosis. The results demonstrated $90 \%$ recovery rate in women with BV after probiotics administration. This finding may lead to the use of probiotics capsules as self-use therapy over the shelf. Another study evaluated the efficiency of Lactobacilluscontaining vaginal tablets in treating bacterial $\mathrm{BV}$ and in restoring vaginal microbiota. A double-blind, placebo-controlled clinical study was carried out by Mastromarino and his colleagues in 2008 [52]. Thirtynine women with BV were enrolled in the trial and were divided randomly into two groups. The test group received Lactobacillus-vaginal tablets ( $L$. brevis, $L$. salivarius, and L. plantarum) for 7 days daily and was compared with the placebo group. The results proved a remarkable improvement of vaginal microbiome as $83 \%$ of the women in the test group were absolutely free of BV after therapy period, and $17 \%$ showed intermediate level of vaginal flora. The previous experimental data was confirmed by a study conducted by $\mathrm{Ya}$ and coworkers in 2010 that showed the efficacy of exogenous administration of Lactobacillus probiotics in treating BV and restoring healthy vaginal microbiome. These data were followed by many other studies that all verified the eminence of exogenous probiotics in curing bacterial vaginosis and restoration of vaginal normal flora.
Ling and colleagues [53] proved that probiotics administration has better effect, as long-term therapy, than the classical antibiotic (metronidazole) in treating BV. They found that probiotics enhance vaginal homeostasis in a gradual manner by suppressing the overgrowth of harmful bacterial strains, thus providing steady restoration of vaginal microbiome.

A recent study aimed to investigate the efficiency of long-term Lactobacillus administration in restoring vaginal microbiota. The study used 250 non-pregnant women with BV, over 9 months. The patients were divided into two groups: group A received standard antibiotic treatment (metronidazole) while group B received antibiotics followed by Lactobacillus rhamnosus. The results showed that group B was more successful in preventing BV recurrence compared to group A that received antibiotic therapy only. These data suggested the pivotal role of Lactobacillus as a prophylactic therapy in suppressing BV recurrence, after antibiotic treatment [54].

\section{Assisted reproductive technology}

As discussed previously, BV is a major cause of infertility worldwide, as it stimulates many other diseases like endometriosis, pelvic inflammatory disease, and tubal blockage as well as elevating the risk of STDs [55]. Therefore, the term BV is misleading, since it is not restricted to the vagina only, but it spreads all over the lower and upper female reproductive tract [56]. Earlier research reported that success of in vitro fertilization (IVF) cycle is highly related to the composition of the vaginal microflora at the time of embryo transfer [57]. The role of Lactobacillus species in improving fertility was profoundly demonstrated in an ART study which found that higher pregnancy rate after IVF cycles was in patients with vaginal microbiome consisting entirely of Lactobacillus sp. The cohort study showed that out of 84 women who underwent IVF cycles, only $8 \%$ of them with bacterial vaginosis (Gardnerella vaginalis and/or Atopobium vaginae) were able to conceive, compared to $40 \%$ clinical pregnancy rate in healthy women [58]. Nevertheless, a randomized controlled trial was performed to investigate the prophylactic action of antibiotic (co-amoxiclav) in IVF patients prior to embryo transfer. A total of 350 patients were enrolled in the study, and the results showed a significant reduction of microbial contamination of catheter tip after embryo transfer between the group which received antibiotics and the control group although no difference in clinical pregnancy was detected between the two groups [59]. This finding can be explained by the ability of the antibiotics to decrease the bacterial load, but they do not reduce the bacterial residues that still affect the immunity system [60]. Moreover, other studies showed that 
colonizing embryo catheter tip with Lactobacillus sp. at the time of embryo transfer may lead to higher implantation rate and live birth rate, by lowering the intrauterine infection rate [61].

Another study reported the positive effect of Lactobacillus supplementation in mitigating the inflammation in patients with polycystic ovary syndrome (PCOS), and consequently improving their fertility. PCOS is a common but treatable endocrine disorder that is characterized by an excess secretion of testosterone hormone, elevation of inflammation, ovarian dysfunction, and hence infertility. This recent study was carried out to investigate the effect of probiotic supplementation in amelioration of inflammation accompanied with PCOS. The results showed a reduction of IL- 6 and hs-CRP and a significant increase in IL-10 level in the test group that received probiotic supplementation compared to the placebo group. On the other hand, no significant change was detected in TNF- $\alpha$ level in the test group. The previous results support the role of probiotics in alleviating the inflammation and hence improving the fertility of PCOS patients [62].

\section{Pre-term birth in pregnancy}

During a healthy pregnancy, the vagina shows more stable and well-balanced ecosystem dominated by Lactobacillus sp. An earlier study conducted by Hillier and colleagues in 1995 [63] found a strong relationship between bacterial vaginosis and pre-term delivery of lowbirth weight infants. A recent study that included 593 pregnant women was carried out to investigate the prevalence of unbalanced vaginal microflora in different trimesters of pregnancy, and to examine the effect on miscarriage or pre-term delivery. They reported a significant relationship between abnormal vaginal microflora and pre-term birth (PTB) in the second trimester before 28 weeks. Klebsiella pneumoniae was characterized as the major bacteria that causes PTB before 28 weeks of gestation [64]. The presence of BV associated bacteria like Gardnerell avaginalis, Bacteroides spp., Peptococcus spp., Staphylococcus epidermidis, Streptococcus agalactiae, and Ureaplasma urealyticum is an indication also of early post-partum endomitritis [65]. Approximately $40-50 \%$ of pre-term births are related to bacterial infection. The absence of vaginal Lactobacilli sp. and proliferation of anaerobic pathogenic bacteria will lead to alteration of defense mechanism and may promote degradation of cervical barrier which provokes the pathogenic invasion of the amniotic fluid and endometrium. Eventually, myometrial contractions may be stimulated and pre-term delivery could be induced [66]. Using next generation sequencing (NGS), a new technology used recently to study the microbiome of the vagina as well as the internal cavity of the uterus, showed that microbial dysbiosis may form a serious risk on the embryo during pre-implantation stage and in maintaining a healthy pregnancy [67].

A Cochrane review was carried out in which 7847 women were diagnosed with bacterial vaginosis and underwent antibiotic therapy. The study pointed out that antibiotic therapy has a positive effect in reducing BV during pregnancy and diminishing the risk of late miscarriage treatment. Nevertheless, it could not eliminate the risk of pre-term birth before 37 weeks, or the risk of pre-term membrane rupture prior to delivery [68]. Probiotics use may minimize pregnancy complications like pre-eclampsia and PTB. A meta-analysis report supports the use of probiotics as prophylaxis for preventing BV recurrence in healthy women with previous history of BV incidence. The results showed that probiotics use has a progressive impact on BV amelioration. In addition, probiotics use is preferred over antibiotics, because probiotics can be used for a long term without any side effect, particularly the impairment of the normal bacterial microbiome [69].

\section{Menopausal vaginal infection}

Estrogen metabolizing activity of gastrointestinal (GI) bacteria is highly associated with the function of the reproductive system. Their enzymatic activity is necessary for estrogen processing, either by releasing it back to the circulation or by excretion through urine or fecal wastes in a process called enterohepatic circulation. The bacteria involved in this regulation process are called estroblome [70]. Deficiency of estrogen and progesterone will decrease the thickness and elasticity of vaginal tissues in approximately $47 \%$ of menopausal women [71]. It was reported that $56 \%$ of women in menopause age have imbalance vaginal flora with dominant species other than Lactobacillus spp. [72]. In a study carried out in China, 92 fertile women and 22 menopausal healthy women were enrolled. It was found that only 3\% of fertile women possess one Lactobacillus sp. while $97 \%$ of the fertile women have 2 or 3 species of Lactobacillus spp. On the other hand, $91 \%$ of the menopausal women showed only one species of Lactobacillus, while $9 \%$ of them demonstrated 2 species of Lactobacillus [73]. A recent review from Korea indicated that L. crispatus is the most frequent colonizing species in healthy women with antimicrobial activity, which was suggested to be used as a probiotic therapeutic alternative to antibiotics in $\mathrm{Ko}-$ rean women [74].

\section{Conclusions}

Several evidence-based studies highlight the significant contribution of probiotics in reinforcement of body health, in general, and in enhancement of fertility, in particular. Probiotics efficiency in fertility boosting is 
addressed on two levels: the first level is male fertility restoration by reversing the adverse impact of oxidative stress induced by fatty diet and old age, affecting negatively testosterone level and sperm quality, and the second level is female fertility improvement. The pivotal role of the vagina as a first-line guard of infections that may ascend to the upper reproductive tract has stimulated scientists to identify and characterize the composition of the vaginal flora. The latest technologies, such as next generation sequencing (NGS), have been utilized for this purpose. It is now well known that presence of predominant Lactobacillus species is considered a health biomarker of symbiotic equilibrium of female genital tract. Pathogenic invasion of the vagina and imbalance of vaginal homeostasis have been found to alter the predominance of beneficial Lactobacillus species, leading to several gynecological complications, such as bacterial vaginosis, pre-term birth in pregnancy, menopausal infection, and infertility. Further research is still needed to investigate the potential role of probiotics as natural anti-pathogenic supplements and fertility boosting agents. Moreover, robust in vivo experiments on probiotics should be performed to elucidate their various modes of action, methods of administration, and synergetic action with antibiotics, to improve male and female fertility potency.

\section{Abbreviations}

IVF: In vitro fertilization; FAO: Food and Agriculture Organization; ISAPP: International Scientific Association for Probiotics and Prebiotics; FOS: Fructo-oligosaccharide; GIT: Gastrointestinal tract; WHO: World Health Organization; HMP: Human Microbiome Project; VMB: Vaginal microbiome; ART: Assisted reproductive technology; AMP: Antimicrobial peptides; ROS: Reactive oxygen species; FSH: Follicle stimulating hormone; LH: Luteinizing hormone; BV: Bacterial vaginosis; STDs: Sexually transmitted diseases; UTIs: Urinary tract infections; PCOS: Polycystic ovary syndrome; PTB: Pre-term birth; NGS: Next generation sequencing; GI: Gastrointestinal

\section{Acknowledgements}

Not applicable.

\section{Authors' contributions}

N.Y. performed the literature review and wrote the manuscript, and A.M. critically revised the article. All authors have read and approved the final manuscript.

\section{Funding}

None.

Availability of data and materials

Not applicable.

Ethics approval and consent to participate

Not applicable.

\section{Consent for publication}

Not applicable.

\section{Competing interests}

The authors declare that they have no competing interests.
Received: 18 August 2020 Accepted: 8 September 2020

Published online: 21 October 2020

\section{References}

1. Kechagia M, Basoulis D, Konstantopoulou S, Dimitriadi D, Gyftopoulou K, Skarmoutsou N, Fakiri E (2013) Health benefits of probiotics: a review. ISRN Nutrition:1-7

2. Marco M, Heeney D, Binda S, Cifelli C, Cotter P, Foligne B, Ganzle M, Kort R, Pasin G, Pihlanto A, Smid E, Hutkins R (2017) Health benefits of fermented foods: microbiota and beyond. Curr Opin Biotechnol 44:94-102

3. Wang B, Yao M, Lv L, Ling Z, Li L (2017) The human microbiota in health and disease. Engineering 3:71-82

4. Mahasneh A, Abbas M (2015) Probiotics: the possible alternative to disease chemotherapy. In: Microbial biotechnology, Progress and Trends. CRC Press: Taylor and Francis Group, pp 213-238

5. Lilly D, Stillwell R (1965) Probiotics: growth-promoting factors produced by microorganisms. Science 147:747-748

6. Joint FAO/WHO Working Group Report on Drafting Guidelines for the Evaluation of Probiotics in Food. London, Ontario, Canada, April 30 and May 1. 2002

7. Salvin J (2013) Fiber and probiotics: mechanisms and health benefits. Nutrients 5:1417-1435

8. Yan F, Polk D (2011) Probiotics and immune health. Curr Opin Gastroenterol 27(6):496-501

9. Buffie C, Pamer E (2013) Microbiota-mediated colonization resistance against intestinal pathogens. Nat Rev Immunol 13(11):790-801

10. Varankovich N, Nickerson M, Korber D (2015) Probiotics-based strategies for therapeutic and prophylactic use against multiple gastrointestinal diseases. Front Microbiol 6:1-14

11. Inhorn M, Patrizio P (2015) Infertility around the globe: new thinking on gender, reproductive technologies and global movements in the $21^{\text {st }}$ century. Hum Reprod Update 21(4):411-426

12. Dardmeh F, Alipour H, Gazerani P, Horst G, Brandsborg E, Ingolf Nielsen H (2017) Lactobacillus rhamnosus PB01 (DSM 14870) supplementation affects markers of sperm kinematic parameters in a diet-induced obesity mice model. PLoS One 12(10):1-17

13. NIH HMP Working Group, Peterson J, Garges S, Giovanni M, Mclnnes P, Wang L, Schloss J, Bonazzi V, McEwen J, Wetterstrand K, Deal C, Di Francesco V, Howcroft T, Karp R, Lunsford R, Wellington C, Belachew T, Wright M, Giblin C, David H, Mills M, Salomon R, Mullins C, Akolkar B, Begg L, Davis C, Grandison L, Humble M, Khalsa J, Little A, Peavy H, Pontzer C, Portnoy M, Sayre M, Starke-Reed P, Zakhari S, Read J, Watson B, Guyer M, NIH HMP Working Group (2009) The NIH Human Microbiome Project. Genome Res 19(12):2317-2323

14. Ravel J, Gajer P, Abdo Z, Schneider M, Koenig S, McCulle S, Karlebach S, Gorle R, Russell J, Tacket C, Brotman R, Davis C, Ault K, Peralta L, Forney L (2011) Vaginal microbiome of reproductive-age women. Proc Natl Acad Sci U S A 108(1):4680-4687

15. Ohri M, Prabha V (2005) Isolation of a sperm-agglutinating factor from Staphylococcus aureus isolated from a woman with unexplained infertility. Fertil Steril 84(5):1539-1541

16. Anukam K, Osazuwa E, Osemene G, Ehigiagbe F, Bruce A, Reid G (2006) Clinical study comparing probiotic Lactobacillus GR-1 and RC-14 with metronidazole vaginal gel to treat symptomatic bacterial vaginosis. Microbes Infect 8(12-13):2772-2776

17. Atassi F, Brassart D, Grob P, Graf F, Servin A (2006) Lactobacillus strains isolated from the vaginal microbiota of healthy women inhibit Prevotella bivia and Gardnerella vaginalis in coculture and cell culture. FEMS Immunol Med Microbiol 48:424-432

18. Juarez T, Ocana M, V. Wiese B, Nader-Macias M (2003) Growth and lactic acid production by vaginal Lactobacillus acidophilus CRL 1259, and inhibition of uropathogenic Escherichia coli. J Med Microbiol 52: 1117-1124

19. Barbonetti A, Cinque B, Vasallo M, Mineo S, Francavilla S, Cifone M, Francavilla F (2011) Effect of vaginal probiotic Lactobaciili on in vitroinduced sperm lipid peroxidation and its impact on sperm motility and viability. Fertil Steril 95(8):2485-2488

20. Pascual L, Daniele M, Giordano W, Pajaro M, Barberis I (2008) Purification and partial characterization of novel bacteriocin L23 produced by Lactobacillus fermentum L23. Curr Microbiol 56:397-402 
21. Bhandari P, Rishi P, Prabha V (2014) Potential of probiotic Lactobacillus plantarum 2621 for the management of infertility. Br Microbiol Res J 4(12): 1585-1596

22. Rose W, McGowin C, Spagnuolo R, Eaves-Pyles T, Popov V, Pyles R (2012) Commensal bacteria modulate innate immune responses of vaginal epithelial cell multilayer cultures. PLoS One 7

23. Magnusdottir E, Thorsteinsson T, Thorsteinsdottir S, Heimisdottir M, Olafsdottir K (2005) Persistent organochlorines sedentary occupation, obesity and human male subfertility. Hum Reprod 20:208-215

24. Giagulli V, Kaufman J, Vermeulen A (1994) Pathogenesis of the decreased androgen levels in obese men. J Clin Endocrinol Metab 79(4):997-1000

25. Midzak A, Chen H, Papadopoulos V, Zirkin B (2009) Leydig cell aging and the mechanisms of reduced testosterone synthesis. Mol Cell Endocrinol 299:23-31

26. Ljiljak D, Milaković T, Severinski N, Kuna K, Radojčić A (2012) Sperm cell in ART. In: Wu B (ed) Advances in embryo transfer. In Tech, Croatia, pp 65-73

27. Sreekumar R, Unnikrishnan J, Fu A, Nygren J, Short K, Schimke J, Barazzoni R, Nair KS (2002) Impact of high-fat diet and antioxidant supplement on mitochondrial functions and gene transcripts muscle. Am J Physiol Endocrinol Metab 282(5):1055-1061

28. Gagnon C, Iwasaki A, De Lamirande E, Kowalski N (1991) Reactive oxygen species and human spermatozoa. Ann N Y Acad Sci 637(1):436-444

29. Ibrahim H, Zhu Y, Wu C, Lu C, Ezekwe M, Liao S, Huang K (2012) Seleniumenriched probiotics improves murine male fertility compromised by high fat diet. Biol Trace Elem Res 147:251-260

30. Chen X, Gong L, Xu J (2013) Antioxidative activity and protective effect of probiotics against high-fat diet-induced sperm damage in rats. Animal 7(2): 287-292

31. Poutahidis T, Springer A, Levkovich T, Qi P, Varian B, Lakritz J, Ibrahim Y, Chatzigiagkos A, Alm E, Erdman S (2014) Probiotic microbes sustain youthful serum testosterone levels and testicular size in aging mice. PLoS One 9:1

32. Zeitoun M, Farahna M, Al-Sobayil K, Abdel-Salam A (2014) Impact of the aqueous extract of dandelion, probiotic and their synbiotic on male lamb's testicular histopathology relative to semen characteristics. Open J Anim Sci 4(1):23-30

33. Valcarce D, Genoves $S$, Riesco M, Martorell P, Herraez M, Ramon D, Robles V (2017) Probiotic administration improves sperm quality in asthenozoospermic human donors. Benificial Microbes 8:2

34. Maretti C, Cavallini G (2017) The association of probiotic with a prebiotic (Flortec, Bracco) to improve the quality/quantity of spermatozoa in infertile patients with idiopathic oligoasthenoteratospermia: a pilot study. Andrology 5:439-444

35. Tremellen K (2016) Gut endotoxin leading to a decline in Gonadal function (GELDING) - a novel theory for the development of late onset hypogonadism in obese men. Basic Clin Androl 26:7

36. Tremellen K, McPhee N, Pearce K (2017) Metabolic endotoxaemia related inflammation is associated with hypogonadism in overweight men, Basic Clin. Androl 27(5)

37. Tirandaz H, Ebrahim-Habib M, Moradvisi B, Raoof S, Sleh-Najafabadi A, Mohammadi E (2018) Microbiota potential for the treatment of sexual dysfunction. Medical Hypothesis 115:46-49

38. Centers for Disease Control and Prevention. Infertility. Last updated July 15, 2016.

39. Mendling W (2016) Vaginal microbiota. AdvExp Med Bio 902:83-93

40. Petrova M, Lievens E, Malik S, Imholz N, Labeer S (2015) Lactobacillaus species as biomarkers and agents that can promote various aspects of vaginal health. Front Physiol 6:81

41. Verhelst R, Verstraelen H, Claeys G, Verschraegen G, Van Simaey L, De Ganck G, De Backer E, Temmerman M, Vaneechoutte M (2005) Comparison between Gram stain and culture for the characterization of vaginal microflora: definition of a distinct grade that resembles grade I microflora and revised categorization of grade I microflora. BMC Microbiol 5:61

42. Fettweis J, Alves J, Borzelleca J, James P, Brooks J, Friedline C, Gao Y, Gao X, Girerd P, Harwich M, Hendricks S, Jefferson K, Huan Mo V, Neale M, Puma F, Reimers M, Rivera M, Roberts S, Myrna G, Serrano M, Sheth N, Silberg J, Voegtly L, Prom-Wormley XB, York T, Cornelissen C, Strauss J, Eaves L, Buck $G$ (2010) The vaginal microbiome: disease, genetics and the environment. Nat Genet 42:729

43. Srinivasan S, Liu C, Mitchell CM, Fiedler T, Thomas K, Agnew K, Marrazzo J, Fredricks D (2010) Temporal variability of human vaginal bacteria and relationship with bacterial vaginosis. PLoS One 5(4):1-8
44. Santiago G, Tency I, Verstraelen $H$, Verhelst $R$, Trog M, Temmerman M Vancoillie L, Decat E, Cools P, Vaneechoutte M (2012) Longitudinal qPCR study of the dynamics of L. crispatus, L. iners, A. vaginae, (sialidase positive) G. vaginalis, and P. bivia in the vagina. PLoS One 7(9):1-9

45. Fredricks D, Fiedler T, Marrazzo J (2005) Molecular identification of bacteria associated with bacterial vaginosis. N Engl J Med 353:1899-1911

46. Wiggins R, Hicks S, Soothhill P, Millar M, Corfield A (2001) Mucinases and sialidases: their role in the pathogenesis of sexually transmitted infections in the female genital tract. Sex Transmlnf 77:402-408

47. Harwich M Jr, Alves J, Buck G (2010) Drawing the line between commensal and pathogenic Garderella vaginalis through genome analysis and virulence studies. BMC Genomics 11:375

48. Brotman RM (2011) Vaginal microbiome and sexually transmitted infections: an epidemiologic perspective. J Clin Invest 121(12):4610-4617

49. Van Oostrum N, De Sutter P, Meys J, Verstraelen H (2013) Risks associated with bacterial vaginosis in infertility patients: a systematic review and metaanalysis. Hum Reprod 28(7):1809-1815

50. Bhandari P, Prabha V (2015) Evaluation of profertility effect of probiotic Lactobacillus plantarum 2621 in a murine model. Indian J Med Res 142(1): 79-84

51. Bhandari P, Rishi P, Prabha V (2016) Positive effect of probiotic Lactobacillus plantarum in reversing LPS-induced infertility in a mouse model. J Med Microbiol 65:345-350

52. Mastromarino P, Macchia S, Meggiorini L, Trinchieri V, Mosca L, Perluigiand M, Midulla C (2008) Effectiveness of Lactobacillus-containing vaginal tablets in the treatment of symptomatic bacterial vaginosis. Eur Soc Clin Microbiol Infect Dis CMI 15:67-74

53. Ling Z, Liu X, Chen W, Luo Y, Yuan L, Hia Y, Nelson K, Huang S, Zhang S, Wang Y, Yuan J, Li L, Xiang C (2013) The restoration of the vaginal microbiota after treatment for bacterial vaginosis with metronidazole or probiotics. Microb Ecol 65:773-780

54. Recine N, Palma E, Domenici L, Giorgini M, Imperiale L, Sassu C, Muselle A, Marchetti C, Muzii L, Benedetti Pacini P (2015) Restoring vaginal microbiota: biological control of bacterial vaginosis. A prospective case-control study using Lactobacillus rhamnosus BMX54 as adjuvant treatment against bacterial vaginosis. Arch Gynecol Obstet 293(1):101-107

55. Kroon S, Ravel J, Huston W (2018) Cervico vaginal microbiota women's health, and reproductive outcomes. Fertil Steril 110(3):327-336

56. Leitich H, Kiss $H$ (2007) Asymptomatic bacterial vaginosis and intermediate flora as risk factors for adverse pregnancy outcome. Best Pract Res Clin Obstet Gynaecol 21(3):375-390

57. Hyman $\mathrm{R}$, Herndon $\mathrm{C}$, Jiang $H$ (2012) The dynamics of the vaginal microbiome during infertility therapy with in vitro fertilization-embryo transfer. J Assist Reprod Genet 29(2):105-115

58. Haahr T, Jensen J, Thomsen L (2016) Abnormal vaginal microbiota may be associated with poor reproductive outcomes: a prospective study in IVF patients. Hum Reprod 31(4):795-803

59. Brook N, Khalaf Y, Coomarasamy A, Edgeworth J, Bradue P (2006) A randomized controlled trial of prophylactic antibiotics (co-amoxiclav) prior to embryo transfer. Hum Reprod 21(11):2911-2915

60. Franasiak J, Scott R (2015) Reproductive tract microbiome in assisted reproductive technologies. Fertil Steril 104(6):1364-1371

61. Sirota I, Zarek S, Segars J (2014) Potential influence of the microbiome on infertility and assisted reproductive technology. Semin Reprod Med 32(1):35-42

62. Ghanei N, Rezaei N, Amiri G, Zayeri F, Makki G (2018) The probiotic supplementation reduced inflammation in polycystic ovary syndrome: a randomized, double-blind, placebo-controlled trial. Journal of functional food 42:306-311

63. Hillier, S. Nugent, R. Eschenbach, D., Krohn, M. Gibbs, R. Martin, D. Cotch, M. Edelman, R. Pastorek and J. Rao, A. (1995), Association between bacterial vaginosis and preterm delivery of a low-birth-weight infant. The Vaginal Infections and Prematurity Study Group. New England J Med. ;333(26):1737_ 1742

64. Son K, Kim M, Kim Y, Kim S, Choi S, Oh S, Roh C (2018) Prevalence of vaginal microorganisms among pregnant women according to trimester and association with preterm birth. Obstet Gynecol Sci 61(1):38-47

65. Maclntyre D, Chandiramani M, Lee $Y$ (2015) The vaginal microbiome during pregnancy and the postpartum period in a European population. Sci Rep 5

66. Witkin S (2015) The vaginal microbiome, vaginal anti-microbial defense mechanisms and the clinical challenge of reducing infection-related preterm birth. BJOG 122(2):213-218 
67. Moreno I, Simon C (2018) Relevance of assessing the uterine microbiota in infertility. Fertil Steril 110(3):337-343

68. Brocklehurst P, Gordon A, Heatley E, Milan S (2013) Antibiotics for treating bacterial vaginosis in pregnancy. In: Cochrane Database Systematic Reviews. (Issue 1). Wiley

69. Ya W, Reifer C, Miller L (2010) Efficacy of vaginal probiotic capsules for recurrent bacterial vaginosis: a double-blind, randomized, placebocontrolled study. Am J Obstet Gynecol 203(2):120-126

70. Plottel C, Blaser M (2011) Microbiome and malignancy. Cell Host Microbe 10:324-335

71. Johnston S, Farrell S, Bouchard C, Farrell S, Beckerson L, Comeau M (2004) The detection and management of vaginal atrophy. J Obstet Gynaecol Can 26:503-515

72. Taylor-Robinson D, McCaffrey M, Pitkin J, Lamont R (2002) Bacterial vaginosis in climacteric and menopausal women. Int J STD AIDS 13:449-452

73. Zhang R, Daroczy K, Xiao B (2012) Qualitative and semi quantitative analysis of Lactobacillus species in the vaginas of healthy fertile and postmenopausal Chinese women. J Med Microbiol 61(5):729-739

74. Kim J, Park Y (2017) Probiotics in the prevention and treatment of postmenopausal vaginal infections: review article. J Menopausal Med 23: 139-145

\section{Publisher's Note}

Springer Nature remains neutral with regard to jurisdictional claims in published maps and institutional affiliations.

\section{Submit your manuscript to a SpringerOpen ${ }^{\circ}$ journal and benefit from:}

- Convenient online submission

- Rigorous peer review

- Open access: articles freely available online

High visibility within the field

- Retaining the copyright to your article

Submit your next manuscript at $\boldsymbol{\nabla}$ springeropen.com 